\title{
MEASURING PRODUCTIVITY OF RESEARCH IN ECONOMICS. A CROSS-COUNTRY STUDY USING DEA ${ }^{\#}$
}

\author{
Martin G. Kocher**, Mikuláš Luptácik*, Matthias Sutter** \\ Working Paper No. 77 \\ August 2001
}

\begin{abstract}
Using a sample of 21 OECD-countries we measure productivity in top-edge economic research by using data envelopment analysis (DEA). DEA is a tool for evaluating relative efficiency and is widely used when there are multiple inputs and outputs and one lacks a specific functional form of a production function. The publications in 10 economics journals with the highest average impact factor over the time period 1980-1998 are taken as research output. Inputs are measured by R\&D expenditures, number of universities with economics departments and (as uncontrolled variable) total population. Under constant returns-to-scale the USA are in dominant position with remarkable distance to other countries. Under variable returns-to-scale the efficiency frontier is created by the USA with most productive scale size (MPSS), and by Ireland and New Zealand, which are technical efficient but scale inefficient. All countries - except the USA - display increasing returns-to-scale, which shows that they have a possibility to improve their efficiency by scaling up their research activities.
\end{abstract}

Keywords: research in economics, productivity analysis, cross-country study, data envelopment analysis (DEA)

JEL-Code: A11, A14, C61, D24

\section{Adress of the author:}

* Vienna University of Economics \& B.A. Augasse 2 - 6, 1090 Vienna, Austria mikulas.luptacik@wu-wien.ac.at

** University of Innsbruck Universitätsstrasse 15, A-6020 Innsbruck, Austria martin.kocher@uibk.ac.at matthias.sutter@uibk.ac.at 


\section{Introduction}

Rankings of economists or economic departments are en vogue in recent years. In 2000, for instance, the European Economic Association has awarded contracts for carrying out the task of ranking economics departments throughout Europe and of comparing them with the top US departments. Kalaitzidakis et al. (1999) have already contributed a paper on European economics, providing a ranking of European research institutions based on publications in core journals of economics. Eichenberger and Frey (2000) present a list of Europe's eminent economists based on actual citations of an economist's papers in the Social Science Citation Index (SSCI).

A common feature of these papers as well as related ones (see, for instance, Bairam, 1994; Elliott et al., 1998; Hodgson and Rothman, 1999; Coupé, 2000) is the fact that research output is evaluated by simply adding up appropriately defined output measures like citations or publications. ${ }^{1}$ Needless to say that, from an economic point of view, it would be desirable to incorporate some kind of input measure as well in order to obtain a comparison or meaningful ranking. This basic insight has been taken into account in an increasing number of studies which attempt to rank economics departments by considering as inputs, e.g., faculty size, the ratio of faculty per students, the number of federal grants or the expenditures on library acquisitions (Conroy and Dusansky, 1995; Scott and Mitias, 1996; Thursby, 2000).

By aggregating research output of economics departments on the country level one arrives at country rankings which are of considerable interest for international comparison and have substantial influence on the ongoing debate in several European countries on how to shape and restructure research and research policy in order to remain, but more often to become, internationally competitive in top-edge research. Kirman and Dahl (1994, 1996), Eichenberger et al. (2000) or Kocher and Sutter (2001) regard input measures like, e.g., population, manpower in economics or financial resources on the country level for their country rankings. Although input-adjusted country rankings are definitely preferable over those which count only output data, the former strand of literature still exhibits a major shortcoming: Input measures are

\footnotetext{
${ }^{1}$ Various methods are used for weighting the output, such as counting American Economic Review standardised pages, giving less weight to shorter papers such as notes and comments, weighting a paper by the journal's impact factor of the respective year, etc.
} 
incorporated by simply weighting output indicators by appropriate input proxies, such as manpower or population, which is a rather crude method of efficiency measurement.

This paper applies a data envelopment analysis (DEA) for a cross-country ranking of top-edge research output in economics. DEA is a linear programming approach, widely used when there are multiple inputs and outputs and one lacks a clear functional relationship between inputs and outputs. Specifically, it is a tool of evaluating relative efficiency, since it first identifies countries on the efficiency frontier and then compares other countries' input-output relationships with those on the frontier. To our knowledge, this is the first paper using DEA to assess the productivity of research in economics for a cross-country study. ${ }^{2}$ It allows to rank countries according to their research productivity and to single out the driving forces for inefficiencies.

The remainder of the paper is organized in the following way. Section 2 provides a brief overview of the selected journals and the arguments for their selection. Additionally, it gives detailed information on the data base. Section 3 shortly reports on prior results and displays a broad-brush picture by applying the traditional method of simply weighting output indicators by input measures. In Section 4 we introduce the DEA-approach and explain our model choices. Section 5 presents the productivity results derived by DEA and discusses the results as well as the sources for inefficiencies in some countries. Finally, Section 6 concludes the paper.

\section{Journal selection and output data base}

The choice of an appropriate output measure for evaluating the efficiency of research on the country level is the starting point for our study. Though research output comprises more than that, it is widely agreed upon among economists that the most important part of research output are publications in scientific journals and that the more visible and the higher esteemed those journals are, the higher is the appreciation of a publication therein.

Due to the enormous and ever increasing number of economics journals it is clearly necessary to select a subset of journals to arrive at a tractable data base of research output in economics. The selection procedure in most related studies is more or less arbitrary, which is not an entirely convincing procedure to arrive at a journal sample,

\footnotetext{
${ }^{2}$ Note that Burton and Phimister (1995) as well as Thursby (2000) employ a DEA-approach to rank economics journals and US economics departments, respectively.
} 
because it leaves room for some kind of discretion. ${ }^{3}$ Therefore, we rely on an objective measure of a journal's visibility, which permits not much arbitrariness or discretion, since it is readily available for any researcher. The journal impact factors ${ }^{4}$, annually published in the Journal Citations Reports (JCR) by the Institute for Scientific Information since 1977 and based on the SSCI, meet these criteria. We decided to choose the 10 journals in the economics section of the JCR with the highest average impact factor over the time period 1980-1998. ${ }^{5}$ By considering almost two decades we want to avoid one of the major shortcomings of several studies in this field, i.e., relying on short time periods such as one to three years.

Table 1 gives an overview of the journals included in our sample. The development of impact factors is very stable over the past two decades (Sutter and Kocher, 2001), which allows us to conclude that the selected journals in this paper stand for foremost visibility of publications in the field of economics.

Table 1

Journal sample

\begin{tabular}{lclc}
\hline \hline Journal & $\begin{array}{c}\text { Average } \mathrm{IF}^{\mathrm{a}} \\
(1980-98)\end{array}$ & Journal & $\begin{array}{c}\text { Average } \mathrm{IF}^{\mathrm{a}} \\
(1980-98)\end{array}$ \\
\hline Journal of Economic Literature & 4.88 & Quarterly Journal of Economics & 1.90 \\
Journal of Financial Economics & 2.74 & Journal of Law and Economics & 1.69 \\
Brookings Papers on Economic Activity & 2.58 & American Economic Review & 1.67 \\
Journal of Political Economy & 2.37 & Journal of Monetary Economics & 1.37 \\
Econometrica & 2.18 & Review of Economic Studies & 1.32 \\
\hline \hline
\end{tabular}

a: IF: Impact factor; Source: Journal Citation Reports (1980-1998).

We restrict ourselves to the even years of our sample period, namely 1980, 1982, 1984, 1986, 1988, 1990, 1992, 1996, and 1998. For the 'top 10' journals, this yields 4950 articles with 7687 entries for authors and a total of 4242 different contributors. We consider all authors of a paper and the institutional affiliations they state first. No articles have been disregarded except editorial notes, obituaries, book reviews and similar non-

\footnotetext{
${ }^{3}$ There is some evidence that this discretion opens opportunities to obtain favourable results, especially when rankings of economics departments, which are quite sensitive to small adjustments, are at stake (see Feinberg, 1998; Griliches and Einav, 1998).

${ }^{4}$ The impact factor is a measure of citations relative to citable items published, including a time lag. See Garfield (1972) for further details and ways of calculating journal impact.

${ }^{5}$ When we started to compile our data the JCR for 1999 and 2000 were not available, yet. Each journal assigned to the economics section in the JCR for 1998 and at least published since 1980 was considered for selection. The Economist has been excluded, because it is generally not considered a scientific journal.
} 
scientific contributions. ${ }^{6}$ These 7687 entries constitute the data base for our study. We do not involve any kind of weighting for multi-authored papers or multi-institutional affiliations, since it would complicate the computations and has been shown to change results only marginally (Kocher and Sutter, 2001).

Table 2displays the composition of our data base entries with regard to the country where the stated institution is located. Results for countries are calculated by aggregating over all authors who state an institution located in the country in question as their first affiliation.

Table 2

Output data

\begin{tabular}{lclc}
\hline \hline Country & $\begin{array}{c}\text { no. of papers in top 10 } \\
\text { journals } 1980-1998\end{array}$ & Country & $\begin{array}{c}\text { no. of papers in top 10 } \\
\text { journals 1980-1998 }\end{array}$ \\
\hline USA & 5963 & Korea & 12 \\
UK & 379 & Taiwan & 12 \\
Canada & 364 & Austria & 9 \\
Israel & 185 & Chile & 9 \\
France & 133 & Ireland & 9 \\
Australia & 66 & Mexico & 7 \\
Belgium & 60 & Russia & 7 \\
Japan & 56 & Denmark & 6 \\
Sweden & 48 & Finland & 6 \\
Germany & 47 & Singapore & 5 \\
Italy & 37 & Argentina & 4 \\
Netherlands & 36 & Portugal & 4 \\
Switzerland & 33 & China & 2 \\
Spain & 32 & Brazil, Greece, Hungary, Turkey & \\
New Zealand & 21 & Bangladesh, Bulgaria, Czech, & \\
India & 17 & Rep., Indonesia, Poland & \\
Hong Kong & 14 & Thailand, Ukraine, Venezuela & \\
Norway & 14 & & \\
\hline \hline Note: Total entries: $7687 ;$ entries with clearly & identifiable affiliation: 7607. & \\
\hline
\end{tabular}

\section{Prior results and stylized facts}

Hodgson and Rothman (1999) report that nearly 80\% of authors in 15 leading journals state an institution located in the United States as their current affiliation. Their results are confirmed by Kalaitzidakis et al. (1999) who rely on ten core journals. The high concentration on the institutional as well as on the country level has raised serious apprehension for the innovative potential and variety in the economics profession. Adjusting pure output data with input measures such as population, number of universities with an economics department or manpower devoted to economics changes

\footnotetext{
${ }^{6}$ We exclude the Papers and Proceedings of the American Economic Review, because, generally, papers published therein do not undergo the standard reviewing process, but are invited contributions.
} 
the picture significantly (see, e.g., Kirman and Dahl, 1994; Eichenberger et al, 2000; Kocher and Sutter, 2001). The gap between US-based contributions and those of other countries appears by far less alarming. The UK does not fare as outstanding as in a mere addition of publications, whereas the performances of Canada, the Scandinavian countries and some smaller European countries improve considerably. Especially Israel seems to be overwhelmingly productive in economics publications. Most bigger European countries like Germany or Spain obviously loose terrain.

Table 3

Input-adjusted output measures - selected countries

\begin{tabular}{|c|c|c|c|c|c|c|c|c|}
\hline Country & $\begin{array}{c}\text { Population } \\
\text { (in } \\
1000 \mathrm{~s})^{\mathrm{a}}\end{array}$ & $\begin{array}{l}\text { Entries per } \\
\text { population } \\
\left(\times 10^{3}\right)\end{array}$ & Country & $\begin{array}{l}\text { no. of } \\
\text { univer- } \\
\text { sities }^{c}\end{array}$ & $\begin{array}{l}\text { Entries } \\
\text { per uni- } \\
\text { versity }\end{array}$ & Country & $\begin{array}{c}\text { man- } \\
\text { power in } \\
\text { economics }\end{array}$ & $\begin{array}{c}\text { Entries } \\
\text { per eco- } \\
\text { nomist }\end{array}$ \\
\hline Israel & 5836 & 31.70 & Israel & 6 & 30.83 & Israel & 150 & 1.23 \\
\hline USA & 267636 & 22.28 & USA & 691 & 8.63 & UK & 482 & 0.79 \\
\hline Canada & 30287 & 12.02 & Canada & 61 & 5.97 & USA & 12000 & 0.50 \\
\hline UK & 59009 & 6.42 & UK & 79 & 4.80 & Sweden & 151 & 0.32 \\
\hline Belgium & 10192 & 5.89 & Belgium & 14 & 4.29 & France & 555 & 0.24 \\
\hline New Zealand & 3761 & 5.58 & Netherlands & 10 & 3.60 & Norway & 118 & 0.12 \\
\hline Sweden & 8849 & 5.42 & Switzerland & 10 & 3.30 & Austria & 99 & 0.09 \\
\hline Switzerland & 7088 & 4.66 & New Zealand & 7 & 3.00 & Ireland & 100 & 0.09 \\
\hline Australia & 18532 & 3.56 & Sweden & 18 & 2.67 & Italy & 455 & 0.08 \\
\hline Norway & 4404 & 3.18 & France & 66 & 2.02 & Netherlands & 585 & 0.06 \\
\hline Ireland & 3661 & 2.46 & Australia & 35 & 1.89 & Germany & 876 & 0.05 \\
\hline Netherlands & 15607 & 2.31 & Norway & 8 & 1.75 & Denmark & 204 & 0.03 \\
\hline France & 58607 & 2.27 & Ireland & 6 & 1.50 & & & \\
\hline Finland & 5140 & 1.17 & Austria & 10 & 0.90 & & & \\
\hline Denmark & 5284 & 1.14 & Denmark & 8 & 0.75 & & & \\
\hline Austria & 8072 & 1.11 & Italy & 50 & 0.74 & & & \\
\hline Spain & 39323 & 0.81 & Spain & 47 & 0.68 & & & \\
\hline Italy & 57563 & 0.64 & Japan & 87 & 0.64 & & & \\
\hline Germany & 82071 & $0.57^{\mathrm{b}}$ & Germany & 77 & 0.61 & & & \\
\hline Japan & 126091 & 0.44 & Finland & 13 & 0.46 & & & \\
\hline Portugal & 9945 & 0.40 & Korea & 30 & 0.40 & & & \\
\hline Greece & 10522 & 0.27 & Mexico & 19 & 0.37 & & & \\
\hline Korea & 45234 & 0.27 & Portugal & 13 & 0.31 & & & \\
\hline Hungary & 10193 & 0.20 & Greece & 8 & 0.25 & & & \\
\hline Czech Rep. & 10315 & 0.10 & Hungary & 8 & 0.25 & & & \\
\hline Mexico & 93182 & 0.08 & Poland & 8 & 0.13 & & & \\
\hline Poland & 38618 & 0.03 & Czech Rep. & 10 & 0.10 & & & \\
\hline
\end{tabular}

${ }^{\text {a }}$ Figures are for 1997. Source: Der Fischer Weltalmanach 2000. Frankfurt am Main, October 1999.

b Excluding population of the former German Democratic Republic would raise Germany's scores to 0.74.

${ }^{c}$ Source: Economics Departments, Institutes and Research Centers in the World at http://ideas.uqam.ca/EDIRC/index.html

d Sources: USA: Economists employed in education (Stigler et al., 1995, p. 332). Israel: Homepages of economics departments (accessed via: http://ideas.uqam.ca/EDIRC/index.html). Rest: Kirman and Dahl (1994). For France we took the average of reported manpower (380-730).

Using our data for 1980 to 1998 , we can confirm these prior results, as shown in Table 3. Smaller countries climb up the ladder. The USA and the UK remain in top positions despite their very high input figures. Yet, the difference to other countries is 
considerably smaller than one might infer from Table 2. Israel indisputably moves atop irrespective of the applied measure in use. All input-adjusted output measures lead to similar rankings. The Pearson correlation coefficients and the Spearman rank correlation coefficients are all highly significant and well above $0.8 .^{7}$ Nevertheless, one should exercise caution in interpreting these results, because different output/input indices allow for ambiguous interpretation. A more comprehensive method for measuring efficiency in the production of economic research is clearly desirable.

\section{The data envelopment analysis (DEA)}

The problem we are facing now is how to measure the efficiency - defined by the ratio of outputs to inputs - in the above described situation of multiple inputs. Data envelopment analysis initiated by Charnes et al. (1978) builds on the seminal paper by Farrel (1957) and extends the engineering ratio approach to efficiency measures from a single-input, single-output efficiency to multiple-input, multiple-output situations. In such situations, DEA provides a single measure of efficiency and obviates the need to assign prespecified weights to inputs or outputs. The efficiency of a country in our case or of a decision making unit (DMU) in general is measured relative to all other countries (DMUs) under the restriction that all countries (DMUs) lie on or below the efficient frontier. The mathematical programming formulation then accords the evaluated country (DMU) the most favorable weighting of inputs and outputs that the constraints allow.

Let us denote DMUs by index $j=1,2, \ldots, n$. Each DMU uses a varying amount of $m$ different inputs $(i=1,2, \ldots, m)$ described by the vector $\underline{x}_{j}$ to produce $s$ different outputs $(r=1,2, \ldots, s)$ described by the vector $\underline{y}_{j}$. Specifically, $\mathrm{DMU}_{\mathrm{j}}$ consumes amount $x_{i j}$ of input $i$ and produces $y_{r j}$ of output $r$. We assume that $x_{i j} \geq 0$ and $y_{r j} \geq 0$ and further that each DMU has at least one positive input and one positive output value. DEA treats the observed inputs $\underline{x}_{j}$ and outputs $\underline{y}_{j}$ as given constants and chooses values of input and output weights for a particular $\mathrm{DMU}_{0}$ by the following optimization problem:

\footnotetext{
${ }^{7}$ Pearson correlation coefficents: 0.93 (between input measure 1 and 2); 0.86 (1 and 3); 0.88 (2 and 3). Spearman rank correlation coefficients: 0.96 (1 and 2); 0.92 (1 and 3); 0.81 (2 and 3).
} 


$$
\underset{\underline{\mathrm{u}}, \underline{\mathrm{v}}}{\operatorname{maximize}} h_{0}(\underline{u}, \underline{v})=\frac{\sum_{r=1}^{s} y_{r 0} u_{r}}{\sum_{i=1}^{m} x_{i 0} v_{i}}
$$

$$
\begin{array}{rlr}
\text { subject to } \quad \frac{\sum_{r=1}^{s} y_{r j} u_{r}}{\sum_{i=1}^{m} x_{i j} v_{i}} & \\
u_{r} \geq 0 & (j=1,2, \ldots, n) \\
v_{i} \geq 0 & (i=1,2, \ldots, m)
\end{array}
$$

where $u_{r}$ is the weight for output $r$ and $v_{i}$ is the weight given to input $i$.

The fractional program (1) can be thought of as the conceptual DEA model. Using a transformation of the variables the problem (1) can be converted into an ordinary linear program:

$$
\begin{gathered}
\underset{\underline{\mu}, \underline{v}}{\operatorname{maximize}} \quad w_{0}(\underline{\mu})=\sum_{r=1}^{s} y_{r 0} \mu_{r} \\
\sum_{r=1}^{s} y_{r j} \mu_{r}-\sum_{i=1}^{m} x_{i j} v_{i} \leq 0 \quad(j=1,2, \ldots, n) \\
\sum_{i=1}^{m} x_{i 0} v_{i}=1 \\
\mu_{r} \geq 0 \quad(r=1,2, \ldots, s) \\
v_{i} \geq 0 \quad(i=1,2, \ldots, m) .
\end{gathered}
$$

The measures of efficiency described by the problems (1) and (2) are "units invariant" - i.e., they are independent of the units in which the inputs and the outputs are measured, provided these units are the same for every DMU.

Replacing the nonnegativity constraints for the weights in (2) by $v_{i} \geq \varepsilon$ and $\mu_{r} \geq \varepsilon$, where $\varepsilon$ is an infinitesimal constant, we write the so-called CCR ratio model (Charnes - Cooper - Rhodes, 1979): 


$$
\operatorname{maximize} \quad w_{0}(\underline{\mu})=\sum_{r=1}^{s} y_{r 0} \mu_{r}
$$

subject to $\quad \sum_{r=1}^{s} y_{r j} \mu_{r}-\sum_{v=1}^{m} x_{i j} v_{i} \leq 0 \quad(j=1,2, \ldots, n)$

$$
\begin{gathered}
\sum_{v=1}^{m} x_{i j} \mathrm{v}_{i}=1 \\
-v_{i} \leq-\varepsilon \quad(i=1,2, \ldots, m) \\
-\mu_{r} \leq-\varepsilon \quad(r=1,2, \ldots, s) .
\end{gathered}
$$

Its dual problem is

$$
\text { minimize } g_{0}\left(\theta, \underline{s}^{-}, \underline{s}^{+}\right)=\theta-\varepsilon\left(\sum_{i=1}^{m} s_{i}^{-}+\sum_{r=1}^{s} s_{r}^{+}\right)
$$

subject to $\quad \theta x_{i 0}-\sum_{j=1}^{n} x_{i j} \lambda_{j}-s_{i}^{-}=0 \quad(i=1,2, \ldots, m)$

$$
\begin{aligned}
\sum_{j=1}^{n} y_{r j} \lambda_{j}-s_{i}^{+}=y_{r 0} \quad(r=1,2, \ldots, s) \\
\lambda_{j} \geq 0 \quad(j=1,2, \ldots, n) \\
s_{i}^{-} \geq 0 \quad(i=1,2, \ldots, m) \\
s_{r}^{+} \geq 0 \quad(r=1,2, \ldots, s)
\end{aligned}
$$

where $\ddot{e}_{j}$ are the weights of DMUs, $s_{i}^{-}$are the input slacks and $s_{r}^{+}$are the output slacks.

The problem (4) seeks values of $\ddot{e}_{j}$ to construct a composite unit, with outputs $\sum_{j=1}^{n} y_{r j} \lambda_{j}$ and inputs $\sum_{j=1}^{n} x_{i j} \lambda_{j}$. The dual constraints (4.2) imply that even after the proportional reduction of all inputs, the inputs of the evaluated $\mathrm{DMU}_{0}$ cannot be lower than the inputs of the composite unit. According to (4.3), the outputs of the $\mathrm{DMU}_{0}$ cannot be higher than the outputs of the composite unit. The $\mathrm{DMU}_{0}$ will be efficient if and only if the following two conditions are satisfied:
a) $\theta_{0}^{0}=1$
b) $s_{i}^{0}=s_{r}^{0}=0$ for all i and $r$, 
where $\theta_{0}^{0}, s_{i}^{0}, s_{r}^{0}$ denote the optimal values. In other words, the $\mathrm{DMU}_{0}$ will be efficient when it has proved impossible to construct a composite unit that outperforms $\mathrm{DMU}_{0}$. Conversely, if $\mathrm{DMU}_{0}$ is inefficient, the optimal values of $\ddot{e}_{j}$ form a composite unit outperforming $\mathrm{DMU}_{0}$ and providing targets for $\mathrm{DMU}_{0}$ (the peer group or the reference set for $\left.\mathrm{DMU}_{0}\right)$.

The (scalar) variable $\theta_{0}^{0}$ gives us the proportion of all inputs of $\mathrm{DMU}_{0}$ necessary to achieve the given output levels efficiently. In other words, $1-\theta_{0}^{0}$ gives the necessary proportional reduction of all inputs of the $\mathrm{DMU}_{0}$ being evaluated in order to achieve the efficient frontier. This reduction is applied simultaneously to all inputs and results in a radial movement toward the envelopment surface. Because of the focus on maximal movement toward the frontier through proportional reduction of inputs, the models (3) (4) are denoted as input-oriented CCR models.

Due to our primary goal to evaluate research output - taking inputs as given - we apply the alternative DEA model denoted as output-oriented CCR model (CharnesCooper-Rhodes, 1978). It focuses on maximal movement via proportional augmentation of outputs under at most the present inputs. The required linear programming problem is:

$$
\begin{gathered}
\underset{\underline{\mu}, \underline{v}}{\operatorname{minimize}} \quad f_{0}(\underline{\mathrm{v}})=\sum_{i=1}^{m} x_{i 0} \mathrm{v}_{i} \\
\text { subject to } \quad-\sum_{r=1}^{s} y_{r j} \mu_{r}+\sum_{v=1}^{m} x_{i j} \mathrm{v}_{i} \geq 0 \quad(j=1,2, \ldots, n) \\
\sum_{r 0} y_{r} \mu_{r}=1 \\
\mu_{r} \geq \varepsilon \quad(r=1,2, \ldots, s) \\
v_{i} \geq \varepsilon \quad(i=1,2, \ldots, m) .
\end{gathered}
$$

The corresponding dual model is:

$$
\underset{\varphi, \underline{\lambda}, \underline{s}^{+}, \underline{s}^{-}}{\operatorname{maximize}} g_{0}\left(\varphi, \underline{s}^{+}, \underline{s}\right)=\varphi+\varepsilon\left(\sum_{r=1}^{s} s_{r}^{+}+\sum_{i=1}^{m} s_{i}^{-}\right)
$$

subject to $\quad \varphi y_{r 0}-\sum_{j=1}^{n} y_{r j} \lambda_{j}+s_{r}^{+}=0 \quad(r=1,2, \ldots, s)$

$$
\sum_{i=1}^{m} x_{i j} \lambda_{j}+s_{r}^{-}=x_{i 0} \quad(i=1,2, \ldots, m)
$$




$$
\begin{array}{ll}
\lambda_{j} \geq 0 & (j=1,2, \ldots, n) \\
s_{r}^{+} \geq 0 & (r=1,2, \ldots, s) \\
s_{i}^{-} \geq 0 & (s=1,2, \ldots, m)
\end{array}
$$

The variable $\varphi_{0}^{0}$ yields the proportion by which all the $\mathrm{DMU}_{0}$ 's outputs should be produced (under the given input levels) for the $\mathrm{DMU}_{0}$ to be efficient. In other words, $\varphi_{0}^{0}-1$ indicates the necessary proportional increase of all $\mathrm{DMU}_{0}$ 's outputs in order to achieve the efficiency frontier.

The constraint (6.2) indicates that even after a proportional increase of all outputs, the outputs of the evaluated $\mathrm{DMU}_{0}$ cannot be higher than the outputs of the composite unit. According to (6.3), the inputs of the $\mathrm{DMU}_{0}$ cannot be lower than the inputs of the composite unit. Like for the input-oriented model (4) a DMU is efficient if and only if $\varphi_{0}^{0}=1$ and all slack variables, $s_{r}^{+}$and $s_{i}^{-}$, are equal to zero.

The following theorem (Seiford and Thrall, 1990, p. 23) provides the correspondence between solutions for the input-oriented CCR and output-oriented CCR models:

Theorem 1: Let $\left(\theta^{0}, \underline{\lambda}^{0}\right)$ be an optimal solution to model (4). Then $\left(\rho^{*}, \underline{\lambda}^{*}\right)=\left(\frac{1}{\theta^{0}},\left(\frac{1}{\theta^{0}} \underline{\underline{\lambda}}^{0}\right)\right.$ is optimal for (6), and the mapping $(\theta, \underline{\lambda}) \rightarrow\left(\frac{1}{\theta},\left(\frac{1}{\theta} \underline{\underline{\lambda}}\right)\right.$ is a $1-1$ correspondence between the optimal solution of (4) and (6).

It follows from Theorem 1 that both models (4) and (6) yield identical envelopment surfaces and identical sets of efficient and inefficient DMUs. However an inefficient DMU will be projected to different points on the efficiency frontier under the input and output orientations.

Up to this point, we have been dealing with models built on the assumption of constant returns-to-scale (CRS) of activities. Geometrically speaking, all supporting hyperplanes for a CRS efficiency frontier pass through the origin. The extension of the CCR model proposed by Banker et al. (1984) allows to analyze situations where increasing inputs imply more (or less) than proportionally increasing outputs on the 
efficient production surface and separate them from output increases resulting from the elimination of technical inefficiencies.

The mathematical formulation of a DEA model under variable returns-to-scale (VRS) or the Banker - Charnes - Cooper (BCC) model differs from the CCR model by adding the convexity condition $\sum_{j=1}^{n} \lambda_{j}=1$ to the constraints in (4) and (6). The BCC model assumes the convex combination of the observed DMUs as the production possibility set and the BCC score is called local pure technical efficiency (PTE). CRS assumption (without the condition $\sum_{j=1}^{n} \lambda_{j}=1$ ) implies that the radial expansion and reduction of all observed DMUs and the nonnegative combinations are possible and the CCR score is called global technical efficiency (TE). Therefore, comparison of the CCR and BCC scores provides deeper insight into the sources of inefficiency that a DMU might have.

Let $\theta_{C C R}^{0}$ and $\theta_{B C C}^{0}$ denote the CCR and BCC scores of a DMU. The scale efficiency is defined by

$$
S E=\frac{\theta_{C C R}^{0}}{\theta_{B C C}^{0}}=\frac{T E}{P T E}
$$

Using the relationship (7) the (global) technical efficiency (TE) of a DMU is decomposed as

$$
T E=P T E \times S E
$$

The global or overall inefficiency of a DMU is explained by inefficient operation (PTE) or by the scale effect (SE) or by both.

The characterization of the CCR model as "constant returns-to-scale" model is technically correct but somewhat misleading because this model can also be used to determine whether returns-to-scale are increasing or decreasing. This is accomplished by the following theorem proved by Banker and Thrall (1992): ${ }^{8}$

\footnotetext{
${ }^{8}$ In Cooper et al. (2000; Section 5.4) this theorem is proved by eliminating the need for the assumption that $\left(\underline{x}_{0}, \underline{y}_{0}\right)$ is on the efficiency frontier.
} 
Theorem 2: Let $\left(\underline{x}_{0}, \underline{y}_{0}\right)$ be a point on the efficiency frontier. Employing a CCR model in envelopment form to obtain an optimal solution $\left(\lambda_{1}^{0}, \ldots, \lambda_{n}^{0}\right)$, returns-to-scale at this point can be determined from the following conditions,

(i) If $\sum_{j=1}^{n} \lambda_{j}^{0}=1$ in any alternate optimum then constant returns-to-scale prevails.

(ii) If $\sum_{j=1}^{n} \lambda_{j}^{0}>1$ for all alternate optima then decreasing returns-to-scale prevail.

(iii) If $\sum_{j=1}^{n} \lambda_{j}^{0}<1$ for all alternate optima then increasing returns-to-scale prevail.

The relations between BCC and CCR models are described be the following theorem due to Ahn et al. (1989):

Theorem 3: A DMU $U_{0}$ found to be efficient with a CCR model will also be found to be efficient with the corresponding BCC model and constant returns-to-scale prevail at $\mathrm{DMU}_{0}$.

As mentioned in Section 3 one relevant input factor for measuring productivity of research is the number of inhabitants. However, this variable represents a resource over which a country does not have control and cannot alter its level. Thus, we have a socalled uncontrolled or non-discretionary input variable. According to Banker and Morey (1986) the model (4) then takes the following form:

$$
\operatorname{minimize} \quad g_{0}\left(\theta, \underline{s}^{-}, \underline{s}^{+}\right)=\theta-\varepsilon\left(\sum_{i \in D} s_{i}^{-}+\sum_{r=1}^{s} s_{r}^{+}\right)
$$

subject to

$$
\begin{aligned}
& \theta x_{i 0}-\sum_{j=1}^{n} x_{i j} \lambda_{j}-s_{i}^{-}=0, \quad i \in D \\
& x_{i 0}-\sum_{j=1}^{n} x_{i j} \lambda_{j}-s_{i}^{-}=0, \quad i \in N D
\end{aligned}
$$




$$
\begin{array}{rr}
\sum_{j=1}^{n} y_{r j} \lambda_{j}-s_{r}^{+}=y_{r 0} \quad(r=1,2, \ldots, s) \\
\lambda_{j} \geq 0 \quad(j=1,2, \ldots, n) \\
s_{r}^{+} \geq 0 \quad(r=1,2, \ldots, s) \\
s_{i}^{-} \geq 0 \quad(i=1,2, \ldots, m)
\end{array}
$$

The symbols $D$ and $N D$ refer to "discretionary" and "non-discretionary", respectively. In model (9) the non-discretionary variables do not enter directly into the efficiency evaluations. But the slacks for uncontrolled inputs are still useful. They indicate that more output is achievable. Hence, the $\mathrm{DMU}_{0}$ will be $\mathrm{CCR}$ (or BCC) efficient if and only if both of the following conditions are satisfied
a) $\theta^{0}=1$
b) all slacks in the objective are zero.

\section{Efficiency results}

We use a single research output defined by the number of articles published in 10 leading journals in economics (see Section 2). Regarding input factors the number of inhabitants (an uncontrolled variable), manpower in economics and financial resources devoted to economic research would be desirable.

However, it seems next to impossible to obtain reliable and internationally comparable data on financial resources for economic research in different countries. Therefore, we decided to rely on a country's R \& D expenditures in million current PPP \$ (Felderer and Campbell, 1995, p. 139). By taking overall R \& D expenditures we implicitly assume that the same proportion of resources is devoted to economics in each country. Since our country sample comprises only highly developed, industrialized countries, this assumption might not be too far off the road. Figures for R \& D expenditures are for the early 1990ies. Due to this fact we consider only papers published from 1990 to 1998 in our data base in order not to relate R \& D expenditures in the early 1990ies to publications in top journals in the early 1980ies.

Kirman and Dahl (1994) report figures on manpower in economic research for selected European countries. Since figures seem to be only rough approximations for 
some countries ${ }^{9}$ and since only 11 European countries are included, we decided to use the number of universities with at least one economics department as a proxy for manpower in economics.

Table 4

Input and Output Data

\begin{tabular}{|c|c|c|c|c|}
\hline$\overline{\text { Countries }}$ & (IN) Population & $\begin{array}{c}\text { (I) R \& D } \\
\text { expenditures }\end{array}$ & $\begin{array}{l}\text { (I) number of } \\
\text { universities }\end{array}$ & $\begin{array}{c}\text { (O) Papers } \\
1990-1998\end{array}$ \\
\hline USA & 267636 & 41749 & 477 & 3020 \\
\hline UK & 59009 & 6908,3 & 79 & 169 \\
\hline Canada & 30287 & 3612 & 61 & 148 \\
\hline Sweden & 8849 & 1321,8 & 18 & 18 \\
\hline Norway & 4404 & 595,7 & 8 & 7 \\
\hline Ireland & 3661 & 161,5 & 6 & 2 \\
\hline Australia & 18532 & 2211,5 & 35 & 18 \\
\hline Switzerland & 7088 & 1226,6 & 10 & 9 \\
\hline Netherlands & 15607 & 1902,5 & 10 & 20 \\
\hline Belgium & 10192 & 957,4 & 14 & 33 \\
\hline Denmark & 5284 & 636 & 8 & 4 \\
\hline Austria & 8072 & 671,7 & 10 & 4 \\
\hline France & 58607 & 9636 & 66 & 65 \\
\hline Germany & 82071 & 8432,6 & 77 & 18 \\
\hline New Zealand & 3761 & 279,2 & 7 & 7 \\
\hline Spain & 39323 & 1907,9 & 47 & 24 \\
\hline Italy & 57563 & 5353,1 & 50 & 33 \\
\hline Japan & 126091 & 20960,8 & 87 & 26 \\
\hline Finland & 5140 & 692,6 & 13 & 3 \\
\hline Portugal & 9945 & 370,8 & 13 & 3 \\
\hline Greece & 10522 & 272,4 & 8 & 1 \\
\hline
\end{tabular}

Source: Population (in thousands) and number of universities with an economics department: See Table 3.

R \& D expenditures in million current PPP \$: Felderer and Campbell (1995), p. 139.

We were able to collect input data for 21 different countries. Table 4 describes the input and output data used in our efficiency analysis. Using these data, we estimated the relative efficiency for both the (output-oriented) CCR and BCC models with population as a non-controllable input variable (IN). For this purpose the objective function (6.1) will be modified as

$$
\operatorname{maximize} \quad g_{0}\left(\varphi, \underline{s}^{+}, \underline{s}^{-}\right)=\varphi-\varepsilon\left(\sum_{i \in D} s_{i}^{-}+\sum_{r=1}^{s} s_{r}^{+}\right)
$$

\footnotetext{
${ }^{9}$ See the figures for Ireland, Netherlands or France on p. 510 in Kirman and Dahl (1994).
} 
The constraints $(6.2)-(6.4)$ remain unchanged. For the BCC model the condition $\sum_{j=1}^{n} \lambda_{j}=1$ is added. Table 5 shows the results.

Table 5

Results of CCR and BCC models with population as an uncontrolled variable

\begin{tabular}{|c|c|c|c|c|c|c|c|}
\hline$\lambda$ & Countries & CCR & Bench- & $\mathrm{BCC}$ & Benchmarks & $\begin{array}{c}\text { Scale } \\
\text { Efficiency }\end{array}$ & $\begin{array}{l}\text { Returns-to- } \\
\text { scale (RTS) }\end{array}$ \\
\hline 1 & USA & 100.00 & $\lambda_{1}=1.00$ & 100.00 & $\lambda_{1}=1.00$ & 1.00 & CRS \\
\hline 2 & UK & 295.70 & $\lambda_{1}=0.17$ & 277.96 & $\lambda_{1}=0.16 \quad \lambda_{6}=0.84$ & 1.06 & IRS \\
\hline 3 & Canada & 176.54 & $\lambda_{1}=0.09$ & 170.54 & $\lambda_{1}=0.08 \quad \lambda_{6}=0.92$ & 1.04 & IRS \\
\hline 4 & Sweden & 531.28 & $\lambda_{1}=0.03$ & 361.65 & $\lambda_{1}=0.03 \quad \lambda_{6}=0.97$ & 1.47 & IRS \\
\hline 5 & Norway & 615.59 & $\lambda_{1}=0.01$ & 195.14 & $\lambda_{1}=0.01 \quad \lambda_{6}=0.17 \quad \lambda_{15}=0.82$ & 3.15 & IRS \\
\hline 6 & Ireland & 585.93 & $\lambda_{1}=0.01$ & 100.00 & $\lambda_{6}=1.00$ & 5.86 & IRS \\
\hline 7 & Australia & 888.94 & $\lambda_{1}=0.05$ & 837.60 & $\lambda_{1}=0.05 \quad \lambda_{6}=0.95$ & 1.06 & IRS \\
\hline 8 & Switzerland & 703.47 & $\lambda_{1}=0.02$ & 307.01 & $\lambda_{1}=0.01 \quad \lambda_{6}=0.99$ & 2.29 & IRS \\
\hline 9 & Netherlands & 316.56 & $\lambda_{1}=0.02$ & 138.15 & $\lambda_{1}=0.01 \quad \lambda_{6}=0.99$ & 2.29 & IRS \\
\hline 10 & Belgium & 209.78 & $\lambda_{1}=0.02$ & 161.40 & $\lambda_{1}=0.02 \quad \lambda_{6}=0.98$ & 1.30 & IRS \\
\hline 11 & Denmark & $1,150.75$ & $\lambda_{1}=0.02$ & 370.38 & $\lambda_{1}=0.01 \quad \lambda_{6}=0.99$ & 3.11 & IRS \\
\hline 12 & Austria & $1,215.00$ & $\lambda_{1}=0.02$ & 690.76 & $\lambda_{1}=0.01 \quad \lambda_{6}=0.99$ & 1.76 & IRS \\
\hline 13 & France & 642.86 & $\lambda_{1}=0.14$ & 594.55 & $\lambda_{1}=0.13 \quad \lambda_{6}=0.87$ & 1.08 & IRS \\
\hline 14 & Germany & $2,710.00$ & $\lambda_{1}=0.16$ & $2,538.07$ & $\lambda_{1}=0.15 \quad \lambda_{6}=0.85$ & 1.07 & IRS \\
\hline 15 & New Zealand & 288.31 & $\lambda_{1}=0.01$ & 100.00 & $\lambda_{15}=1.00$ & 2.88 & IRS \\
\hline 16 & Spain & 575.05 & $\lambda_{1}=0.05$ & 536.40 & $\lambda_{1}=0.04 \quad \lambda_{6}=0.96$ & 1.07 & IRS \\
\hline 17 & Italy & 959.28 & $\lambda_{1}=0.10$ & 860.41 & $\lambda_{1}=0.09 \quad \lambda_{6}=0.91$ & 1.11 & IRS \\
\hline 18 & Japan & $2,118.53$ & $\lambda_{1}=0.18$ & $2,003.92$ & $\lambda_{1}=0.17 \quad \lambda_{6}=0.83$ & 1.06 & IRS \\
\hline 19 & Finland & $1,672.24$ & $\lambda_{1}=0.02$ & 758.19 & $\lambda_{1}=0.01 \quad \lambda_{15}=0.99$ & 2.20 & IRS \\
\hline 20 & Portugal & 894.60 & $\lambda_{1}=0.01$ & 572.96 & $\lambda_{1}=0.01 \quad \lambda_{6}=0.99$ & 1.56 & IRS \\
\hline 21 & Greece & $1,968.50$ & $\lambda_{1}=0.01$ & $1,004.80$ & $\lambda_{1}=0.01 \quad \lambda_{6}=0.99$ & 1.96 & IRS \\
\hline
\end{tabular}

In the CCR model with population as an uncontrolled variable only the USA are efficient and remain in dominant position with remarkable distance to other countries. Even Canada with the second highest efficiency score should increase the number of publications in the 10 top journals by $76 \%$ or from 61 to 107 papers in order to achieve efficiency.

The USA, the only efficient country in the CCR model is also efficient in the BCC model (as claimed in Theorem 3) and has most productive scale size (MPSS). In the BCC model, Ireland and New Zealand are locally technical efficient, but not globally efficient. The overall (CCR) inefficiency of Ireland and New Zealand is caused by scale inefficiency. Alternatively, the overall inefficiency of Canada (or e.g. UK) is primarily 
caused by its inefficient operation and only to a minor part by the scale effect. Because of $\sum_{j=1}^{n} \lambda_{j}^{0}<1$ from the CCR model Ireland and New Zealand - and all other countries except the USA - display increasing returns-to-scale (IRS). In other words, they have the potential to improve their efficiency by scaling up their activities.

The optimal values of $\lambda_{j}$ in Table 5 (benchmarks) provide the linear combination of the countries, which are located on the efficiency frontier and closest to the particular country. For a large majority of the countries the peer group - under VRS - consists of the USA and Ireland. The projections are very close to Ireland (the coefficient $\lambda_{6}$ is nearly one). The peer group for Sweden and Finland are the USA and New Zealand (with $\lambda_{15}$ very close to one) and for Norway it is the USA, Ireland and New Zealand.

The reader may verify - from equation (6.3.) - that the slack variable for population is positive for most countries (with the exception of Sweden, Norway and Finland), which indicates an additional source for an increase of output.

Because population as the uncontrolled input is highly correlated with both the controlled input variable $\mathrm{R} \& \mathrm{D}$ expenditures and the number of universities we omitted in a second model this input from our calculation and applied the standard output oriented CCR model (6.1) - (6.4) and BCC model (with $\sum_{j=1}^{n} \lambda_{j}=1$ ). The results are given in Table 6. 
Table 6

Results of CCR and BCC models without population as an input variable

\begin{tabular}{|c|c|c|c|c|c|c|c|}
\hline & Countries & CCR & Bench- & $\mathrm{BCC}$ & Benchmarks & $\begin{array}{c}\text { Scale } \\
\text { Efficien }\end{array}$ & Returns-to- \\
\hline 1 & USA & 100.00 & $\lambda_{1}=1.00$ & 100.00 & $\lambda_{1}=1.00$ & 1.00 & CRS \\
\hline 2 & UK & 295.68 & $\lambda_{1}=0.17$ & 277.96 & $\lambda_{1}=0.16 \quad \lambda_{6}=0.84$ & 1.06 & IRS \\
\hline 3 & Canada & 176.54 & $\lambda_{1}=0.09$ & 170.54 & $\lambda_{1}=0.08 \quad \lambda_{6}=0.92$ & 1.04 & IRS \\
\hline 4 & Sweden & 531.28 & $\lambda_{1}=0.03$ & 438.29 & $\lambda_{1}=0.03 \quad \lambda_{6}=0.97$ & 1.21 & IRS \\
\hline 5 & Norway & 615.90 & $\lambda_{1}=0.01$ & 211.65 & $\lambda_{1}=0.01 \quad \lambda_{6}=0.99$ & 2.91 & IRS \\
\hline 6 & Ireland & 585.93 & $\lambda_{1}=0.01$ & 100.00 & $\lambda_{6}=1.00$ & 5.86 & IRS \\
\hline 7 & Australia & 888.94 & $\lambda_{1}=0.05$ & 837.60 & $\lambda_{1}=0.05 \quad \lambda_{6}=0.95$ & 1.06 & IRS \\
\hline 8 & Switzerland & 703.47 & $\lambda_{1}=0.02$ & 307.01 & $\lambda_{1}=0.01 \quad \lambda_{6}=0.99$ & 2.29 & IRS \\
\hline 9 & Netherlands & 316.56 & $\lambda_{1}=0.02$ & 138.15 & $\lambda_{1}=0.01 \quad \lambda_{6}=0.99$ & 2.29 & IRS \\
\hline 10 & Belgium & 209.78 & $\lambda_{1}=0.02$ & 161.40 & $\lambda_{1}=0.02 \quad \lambda_{6}=0.98$ & 1.30 & IRS \\
\hline 11 & Denmark & $1,150.75$ & $\lambda_{1}=0.02$ & 370.38 & $\lambda_{1}=0.01 \quad \lambda_{6}=0.99$ & 3.11 & IRS \\
\hline 12 & Austria & $1,215.07$ & $\lambda_{1}=0.02$ & 690.76 & $\lambda_{1}=0.01 \quad \lambda_{6}=0.99$ & 1.76 & IRS \\
\hline 13 & France & 642.86 & $\lambda_{1}=0.14$ & 594.55 & $\lambda_{1}=0.13 \quad \lambda_{6}=0.87$ & 1.08 & IRS \\
\hline 14 & Germany & $2,710.00$ & $\lambda_{1}=0.16$ & $2,538.07$ & $\lambda_{1}=0.15$ & 1.07 & IRS \\
\hline 15 & New Zealand & 288.31 & $\lambda_{1}=0.01$ & 120.11 & $\lambda_{6}=0.99$ & 2.40 & IRS \\
\hline 16 & Spain & 575.08 & $\lambda_{1}=0.05$ & 536.40 & $\lambda_{1}=0.04$ & 1.07 & IRS \\
\hline 17 & Italy & 959.28 & $\lambda_{1}=0.10$ & 860.41 & $\lambda_{1}=0.09 \quad \lambda_{6}=0.91$ & 1.11 & IRS \\
\hline 18 & Japan & $2,118.60$ & $\lambda_{1}=0.18$ & $2,004.00$ & $\lambda_{1}=0.17 \quad \lambda_{6}=0.83$ & 1.06 & IRS \\
\hline 19 & Finland & $1,672.24$ & $\lambda_{1}=0.02$ & $1,351.35$ & $\lambda_{1}=0.01 \quad \lambda_{15}=0.99$ & 1.24 & IRS \\
\hline 20 & Portugal & 894.57 & $\lambda_{1}=0.01$ & 572.96 & $\lambda_{1}=0.01 \quad \lambda_{6}=0.99$ & 1.56 & IRS \\
\hline 21 & Greece & $1,968.50$ & $\lambda_{1}=0.01$ & $1,005.00$ & $\lambda_{1}=0.01 \quad \lambda_{6}=0.99$ & 1.96 & IRS \\
\hline
\end{tabular}

Results in Table 6 coincide with those in Table 5, the only exceptions being Sweden, Norway, New Zealand and Finland, which achieve a lower efficiency rating (for the BCC model) than in Table 5. In the model with population as an uncontrolled variable (Table 5) New Zealand was efficient and the slack variable for the population was zero for Sweden, Norway and Finland. It is obvious from the comparison of the two tables that the research output deserves a higher efficiency rating when it has been achieved under a relatively tighter constraint.

Summarizing results in Table 5 and Table 6 one can see that eight countries (USA, Ireland, New Zealand, Canada, Belgium, United Kingdom, Netherlands and Norway) belong to the group of 10 countries with the highest efficiency scores in any of the four models considered. Sweden belongs to this group with the exception of the BCC model without population as an uncontrolled variable, Spain under the assumption of constant 
returns-to-scale (CCR-model) and Switzerland under variable returns-to-scale (BCCmodel).

In order to see how sensitive the previous results are with respect to the journal and sample period selection we used the data base of Kocher and Sutter (2001), which contains a broader set of 15 top journals. We took publications in 1992 and 1997 as output. ${ }^{10}$ Output figures as well as the corresponding DEA results are given in Table 7.

Table 7

Results of CCR and BCC models with output data from Kocher and Sutter (2001)

\begin{tabular}{|c|c|c|c|c|c|c|c|c|c|}
\hline & Countries & Papers $^{\mathrm{a}}$ & CCR (IN) & BCC (IN) & $\begin{array}{c}\text { Scale } \\
\text { Efficiency }\end{array}$ & CCR & $\mathrm{BCC}$ & $\begin{array}{l}\text { Benchmarks } \\
\text { for BCC }\end{array}$ & $\begin{array}{c}\text { Scale } \\
\text { Efficiency }\end{array}$ \\
\hline 1 & USA & 1613 & 100.00 & 100.00 & 1.00 & 120.91 & 100.00 & $\lambda_{1}=1.00$ & 1.21 \\
\hline 2 & UK & 323 & 100.00 & 100.00 & 1.00 & 100.00 & 100.00 & $\lambda_{2}=1.00$ & 1.00 \\
\hline 3 & Canada & 103 & 161.86 & 156.47 & 1.03 & 163.96 & 163.70 & $\lambda_{2}=0.51 \quad \lambda_{6}=0.49$ & 1.00 \\
\hline 4 & Sweden & 21 & 250.00 & 183.62 & 1.36 & 294.29 & 280.69 & $\lambda_{2}=0.16 \quad \lambda_{6}=0.84$ & 1.05 \\
\hline 5 & Norway & 8 & 315.56 & 144.00 & 2.19 & 348.15 & 195.72 & $\lambda_{2}=0.03 \quad \lambda_{6}=0.97$ & 1.78 \\
\hline 6 & Ireland & 7 & 107.87 & 100.00 & 1.08 & 107.87 & 100.00 & $\lambda_{6}=1.00$ & 1.08 \\
\hline 7 & Australia & 27 & 377.93 & 349.64 & 1.08 & 382.96 & 381.54 & $\lambda_{2}=0.30 \quad \lambda_{6}=0.70$ & 1.00 \\
\hline 8 & Switzerland & 10 & 394.32 & 243.15 & 1.62 & 408.86 & 243.15 & $\lambda_{2}=0.06 \quad \lambda_{6}=094$ & 1.68 \\
\hline 9 & Netherlands & 22 & 185.85 & 110.52 & 1.68 & 185.85 & 110.52 & $\lambda_{2}=0.06 \quad \lambda_{6}=0.94$ & 1.68 \\
\hline 10 & Belgium & 16 & 279.77 & 260.19 & 1.08 & 279.77 & 260.19 & $\lambda_{2}=0.11 \quad \lambda_{6}=0.89$ & 1.08 \\
\hline 11 & Denmark & 3 & 972.76 & 521.92 & 1.86 & 991.08 & 521.92 & $\lambda_{2}=0.03 \quad \lambda_{6}=0.97$ & 1.90 \\
\hline 12 & Austria & 6 & 523.43 & 405.25 & 1.29 & 523.43 & 405.25 & $\lambda_{2}=0.06 \quad \lambda_{6}=0.94$ & 1.29 \\
\hline 13 & France & 49 & 550.71 & 544.34 & 1.01 & 550.71 & 544.34 & $\lambda_{2}=0.82 \quad \lambda_{6}=0.18$ & 1.01 \\
\hline 14 & Germany & 19 & $1,655.63$ & $1,655.63$ & 1.00 & $1,655.63$ & $1,655.63$ & $\lambda_{2}=0.97 \quad \lambda_{6}=0.03$ & 1.00 \\
\hline 15 & $\begin{array}{l}\text { New } \\
\text { Zealand }\end{array}$ & 1 & 1.305 .48 & 761.04 & 1.72 & $1,305.48$ & $1,132.50$ & $\lambda_{2}=0.01 \quad \lambda_{6}=0.99$ & 1.15 \\
\hline 16 & Spain & 16 & 557.41 & 554.94 & 1.00 & 557.41 & 554.94 & $\lambda_{2}=0.26 \quad \lambda_{6}=0.74$ & 1.00 \\
\hline 17 & Italy & 27 & 757.00 & 731.53 & 1.03 & 757.00 & 731.53 & $\lambda_{2}=0.60 \quad \lambda_{6}=0.40$ & 1.03 \\
\hline 18 & Japan & 20 & $1,779.36$ & $1,745.20$ & 1.02 & $1,779.36$ & $1,745.20$ & $\lambda_{1}=0.02 \quad \lambda_{2}=0.98$ & 1.02 \\
\hline 19 & Finland & 1 & $2,941.18$ & $1,600.00$ & 1.84 & $3,236.25$ & $3,184.71$ & $\lambda_{2}=0.08 \quad \lambda_{6}=0.92$ & 1.02 \\
\hline 20 & Portugal & 3 & 578.03 & 560.22 & 1.03 & 578.03 & 560.22 & $\lambda_{2}=0.03 \quad \lambda_{6}=0.97$ & 1.03 \\
\hline 21 & Greece & 1 & $1,273.88$ & $1,219.51$ & 1.04 & $1,273.88$ & $1,219.51$ & $\lambda_{2}=0.02 \quad \lambda_{6}=0.98$ & 1.04 \\
\hline
\end{tabular}

${ }^{10}$ Kocher and Sutter (2001) provide data for 1977, 1982, 1987, 1992 and 1997 for their selection of 15 journals with the highest average impact factors from 1977 to 1997. In addition to the 10 journals selected in this paper, the Economic Journal, RAND Journal of Economics, Journal of Human Resources, Economic Geography and Economic History Review are included the sample of Kocher and Sutter. 
CCR (IN) and BCC (IN) denote the models with population as an uncontrolled variable. When we compare the results of Tables 5 and 6 with those of Table 7, it becomes obvious that the modification concerning our output measures has only minor impact on the country ranking with respect to efficiency in economic research. Referring to the group of 10 countries with best efficiency scores, New Zealand is replaced by Australia in Table 7. The UK has significantly improved its position and becomes efficient. ${ }^{11}$ Austria, for instance, moves up to $11^{\text {th }}$ place when using the data of Kocher and Sutter (2001).

The peer group for the CCR (IN) model consists of the USA and UK, for the BCC (IN) model of the USA, UK and Ireland. Because the population is a tight constraint (the corresponding slack variable is zero) for the USA, Canada, Sweden, Norway, Australia, Switzerland, Denmark and Finland in the CCR (IN) model, their efficiency scores in the CCR model are lower than in the CCR (IN) model. For all other countries the slack variable for population is positive and therefore the results for the CCR (IN) and CCR model coincide. The CCR model with output data from Kocher and Sutter (2001) is the only case where the USA are no longer at the efficiency frontier and hence lose the leading position. In fact, the USA - and also Japan - have decreasing returns-to-scale in this particular model (which has been omitted in Table 7). The UK, being at the efficiency frontier have constant returns-to-scale, whereas all other countries operate at increasing returns-to-scale. Results for the models BCC (IN) and BCC can be interpreted in a similar vein.

\section{Discussion and conclusion}

The issue of reforming research and education at universities is high on the political agenda in several European countries. The debate always focuses on finding ways to improve efficiency in the academic sector, which is still almost exclusively financed by the public in most (continental) European countries. One of the pronounced aims of reforming the academic sector stated by politicians in Germany and Austria, for instance, is to make researchers working in these countries internationally competitive by improving their efficiency. Despite the ambiguity of the proposed reforms in actually

\footnotetext{
${ }^{11}$ The favourable result for the UK stems from the fact that the sample of 15 top journals includes The Economic Journal which has about $50 \%$ of its authors working in the UK.
} 
promoting this aim, it is also not clear in the political debate how an efficient research output would (and should) look like.

The academic economic literature on measuring research output has not always been of great help, so far. Many studies (such as Hodgson and Rothman, 1999) have concentrated on measuring output without taking into account any inputs. The merit of these studies lies in providing the mere 'facts' on leading institutions or countries. Other studies (like Kirman and Dahl, 1994, or Eichenberger et al., 2000) have normalized research output by various inputs such as population or manpower. One of the most important insights of these studies is the fact that relatively small countries 'produce' very much (top) economic research in relation to their small size. This is in particular true for Israel, but also - to a lesser degree - for Belgium, Sweden or Switzerland.

Yet, so far, there has been no attempt to measure efficiency in economic research by, e.g., estimating a production function. We guess that one reason for the lack of such a study is the fact that a certain production function would be too restrictive, since it might fit some countries rather well, but others only poorly. The approach taken here avoids this possible shortcoming. We have measured cross-country productivity in topedge economic research by using data envelopment analysis (DEA). DEA does not assume a specific functional form of a production function, but measures efficiency of a country relative to all other countries. Each country is accorded the most favorable weighting of inputs or outputs to achieve maximum efficiency, subject only to the restriction that all countries lie on or below the efficiency frontier. We have used two basic, output-oriented models: one with constant returns-to-scale, one with variable returns-to-scale.

Our results confirm by and large the country rankings resulting from previous studies which normalized output by certain inputs. ${ }^{12}$ Yet, the DEA-approach allows to make some judgements on efficiency and the sources of inefficiencies, which is not possible by simply normalizing research output by input indicators. The United States remain the most efficient country in producing top research in economics. One consequence of this is the steady 'flow' of Nobel prize awards to US-based researchers. However, some smaller countries are not far behind. Especially, in all the models with

\footnotetext{
${ }^{12}$ Considering the 21 countries in Table 4, Spearman rank correlations range from 0.73 to 0.85 between input-adjusted rankings in Table 3 (using population and number of universities as inputs) and DEArankings in Tables 5 and 6 . The average absolute rank difference between input-adjusted rankings and the CCR (BCC)-models is 2.5 (3.6).
} 
variables returns-to-scale also Ireland, a comparatively very small country, is efficient in top-edge research. Belgium, the Netherlands, Norway or New Zealand (the latter country being fully efficient when population is included as uncontrolled variable) have also high efficiency scores. The UK, typically considered the second most important nation in economic research, is only efficient when a broader data set, including publications in The Economic Journal, is taken into account. Relatively large and very wealthy countries such as Germany or Japan come out very inefficient, clearly indicating a need for reforms in the academic sector of those countries- provided international competitiveness and efficiency is a serious political goal.

This paper should serve as a starting point for an appropriate measurement of efficiency in economic research across countries. One of its limitations is the use of proxies for manpower in economic research as well as for financial resources devoted to economic research. Better - and internationally consistent - input data would clearly be desirable to obtain a finer-grained picture of the sources of (technical or scale) inefficiency. An interesting avenue for further research, then, would be to investigate how possible inefficiencies could be tackled best.

\section{References}

Ahn, T., Charnes, A., Cooper, W. W. (1989). 'A note on the efficiency characterizations obtained in different DEA models', Socio-Economic Planning Sciences, vol. 22(6), pp. 253-257.

Bairam, E. I. (1994). 'Communication. Institutional affiliation of contributors to top economic journals, 1985-1990', Journal of Economic Literature, vol. 32(2), pp. 674-679.

Banker, R. D., Charnes, A., Cooper, W. W. (1984). 'Some models for estimating technical and scale inefficiencies in data envelopment analysis', Management Science, vol. 30, pp. 1078-1092.

Banker, R. D., Morey R. (1986). 'Efficiency analysis for exogenously fixed inputs and outputs', Operations Research, vol. 34 (4), pp. 513-521.

Banker, R. D., Thrall R. M. (1992). 'Estimating most productive scale size using data envelopment analysis', European Journal of Operational Research, vol. 62(1), pp. 74-84.

Burton, M. P., Phimister, E. (1995). 'Core journals: A reappraisal of the Diamond list', Economic Journal, vol. 105(2), pp. 361-373.

Charnes, A., Cooper, W. W., Rhodes, E. (1978). 'Measuring the efficiency of decision making units', European Journal of Operational Research, vol. 2, pp. 429-444.

Charnes, A., Cooper, W. W., Rhodes, E. (1979). 'Short communication: Measuring the efficiency of decision making units', European Journal of Operational Research, vol. 3, p. 339. 
Conroy, M., Dusansky, R. (1995). 'The productivity of economics departments in the US: Publications in the core journals', Southern Economic Journal, vol. 33(4), pp. 1966-1971.

Cooper, W. W., Seiford, L. M., Tone, K. (2000). Data envelopment analysis. A comprehensive text with models applications. References and DEA-Solver software, Kluwer Academic Publishers (New York).

Coupé, T. (2000). 'Revealed performances. Worldwide rankings of economists and economics departments', Université Libre de Bruxelles. mimeo.

Dusansky, R., Vernon, C. J. (1998). 'Rankings of U.S. economics departments', Journal of Economic Perspectives, vol. 12(1), pp. 157-170.

Eichenberger, R., Frey, B. S. (2000). ‘Europe’s eminent economists: A quantitative analysis‘, University of Zurich, mimeo.

Eichenberger, R., Meier, U., Arpagaus, R. (2000). 'Ökonomen, Publikationen und Zitationen: Ein europäischer Vergleich', Perspektiven der Wirtschaftspolitik, vol. 1(2), pp. 143-160.

Elliott, C., Greenaway, D., Sapsford, D. (1998). 'Who's publishing who? The national composition of contributors to some core US and European journals', European Economic Review, vol. 42(1), pp. 201-206.

Farrel, M. J. (1957). 'The measurement of productive efficiency', Journal of the Royal Statistical Society, Series A, vol. 120, pp. 253-290.

Feinberg, R. M. (1998). 'Correspondence. Ranking economics departments', Journal of Economic Perspectives, vol. 12(4), pp. 231-232.

Felderer, B., Campell, D. F. J. (1995). Die Evaluation der akademischen Forschung im internationalen Vergleich: Strukturelle Trends und Modelle. 1. Zwischenbericht: Patterns of publication output and publication efficiency of 23 developed industrial countries (1980-1993), Institut für Höhere Studien (Wien).

Garfield, E. (1972). 'Citation analysis as a tool in journal evaluation', Science, vol. 178(4060), pp. 471479.

Griliches, Z., Einav, L. (1998). 'Correspondence. Ranking economics departments', Journal of Economic Perspectives, vol. 12(4), p. 233-235.

Hodgson, G. M., Rothman, H. (1999). 'The editors and authors of economics journals: A case of institutional oligopoly?', Economic Journal, vol. 109(2), pp. F165-186.

Kalaitzidakis, P., Mamuneas, T. P., Stengos, T. (1999). 'European economics: An analysis based on publications in the core journals', European Economic Review, vol. 43(4-6), pp. 1150-1168.

Kirman, A., Dahl, M. (1994). 'Economic research in Europe', European Economic Review, vol. 38(34), pp. 505-522.

Kirman, A., Dahl, M. (1996). 'Economic Research in Europe’, EUI (Florence).

Kocher, M. G., Sutter, M. (2001). 'The institutional concentration of authors in top journals of economics during the last two decades', Economic Journal, vol. 111(5), F405-421.

Scott, L. C., Mitias, P. M. (1996). 'Trends in rankings of economics departments in the U.S.: An update', Economic Inquiry, vol.34(2), pp. 378-400. 
Seiford L. M., Thrall, R. M. (1990). 'Recent developments in DEA. The mathematical programming approach to frontier analysis', Journal of Econometrics, vol. 46(1), pp. 7-38.

Stigler, G. J., Stigler, S. M., Friedland, C. (1995). 'The journals of economics', Journal of Political Economy, vol. 103(2), pp. 331-359.

Sutter, M., Kocher, M. G. (2001). 'Tools for evaluating research output: Are citation-based rankings of economics journals stable?', Evaluation Review, forthcoming.

Thursby, J. G. (2000). 'What do we say about ourselves and what does it mean? Yet another look at economic department research', Journal of Economic Literature, vol. 38(2), pp. 383-404. 